\title{
Studying the Optimal Time for Meals to Circadian Rhythms and Body Health (Application to Hospitality Establishments)
}

\author{
Mohammed Nader Shalaby ${ }^{1 *(\mathbb{D})}$, Mona Mostafa Abdo Sakoury ${ }^{2}$, Sherin Hussien $^{3,4} \mathbb{D}$, Maaly Fayad Abdelghani ${ }^{5}$ \\ ${ }^{1}$ Department of Biological Sciences and Sports Health, Faculty of Physical Education, Suez Canal University, Ismailia, Egypt; \\ ${ }^{2}$ Department of General Courses, Faculty of Applied Studies and Community Service, Imam Abd Al-Rahman Al- Faisal \\ University, Dammam, Saudi Arabia; ${ }^{3}$ Department of Health Sciences, Faculty of Education, Western University, London, \\ Canada; ${ }^{4}$ Department of Health Sciences, Faculty of Physical Education for Girls, Alexandria University, Alexandria, Egypt; \\ ${ }^{5}$ Department of Hotel Studies, Faculty of Tourism and Hotels, Alexandria University, Alexandria, Egypt
}

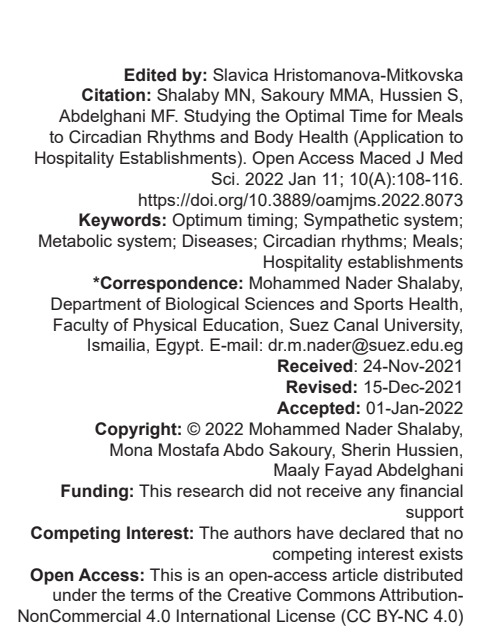

Introduction

The sympathetic nervous system is considered primarily responsible for the activity of the digestive system, as the sympathetic nervous system receives signals of the brightness of the light and translates those signals through the spinal cord to start the process of secretion of digestive enzymes and the process of food metabolism. On the other side, the individuals having their meals (breakfast-lunch-dinner) in non-ideal times due to changes observed in the lifestyle and dietary habits over the past three decades, the last result of technological progress and means of media and the reverse of the times of day and the change in sleeping hours which resulted in nighttime activity inconsistent with biological nature and thus represent the metabolic variable occurs in non-natural appointments that are compatible with the internal environment of the human being and the external environment of nature (human nature of creation), causing the emergence of many diseases of the gastrointestinal tract of sugar, liver, pancreas, irregular heartbeat and obesity which are stated to be caused by the quality of the food only, without relating to the meal timing [1].

The alternating of day and night of the earth's cycle is so reliable that it is not surprising that animals, plants, and bacteria adjust their behavior and physiology (Figures 1 and 2). Circadian rhythms are a ubiquitous adaptation of all organisms to the most predictable of environmental challenges. A biological rhythm that persists under constant conditions and has a period of 1 day is called "circadian" (circa, "around;" dian, "day"). Until very recently, the molecules underlying the oscillation have remained unknown. Perturbations of such oscillations by inhibitors of RNA or protein synthesis suggest that such molecules are involved [2].

The importance of the study is the need for organs of the body compatibility (internal) parasympathetic system, which must be in harmony with the external environment Biological Clock (CIRCADIAN RHYTHM) at the right time to eat three meals as well as the importance of educating and modifying style 


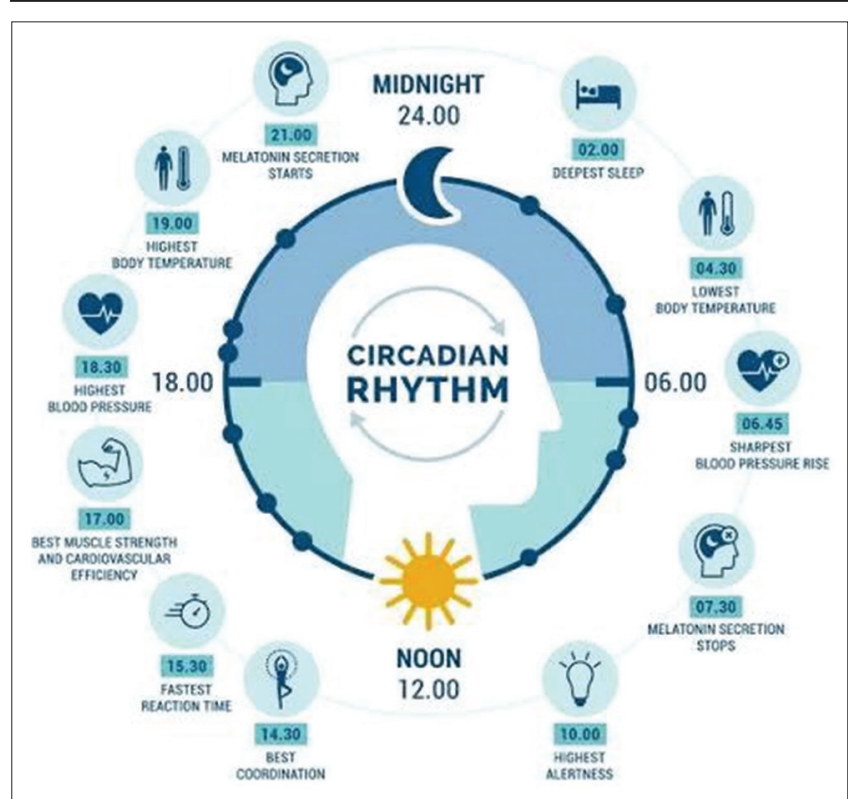

Figure 1: Infographic of a conventional circadian rhythm

behaviors and methodology of individuals at the time of food to reach eating to good health. In addition to modifying the course of hospitality institutions in the necessity of providing healthy food at the appropriate time for the hotel guests in a simultaneous healthy and biological way. Sleeping is a significant component of human health needs and supports hotel guests recover physically and psychologically from their trip [3].

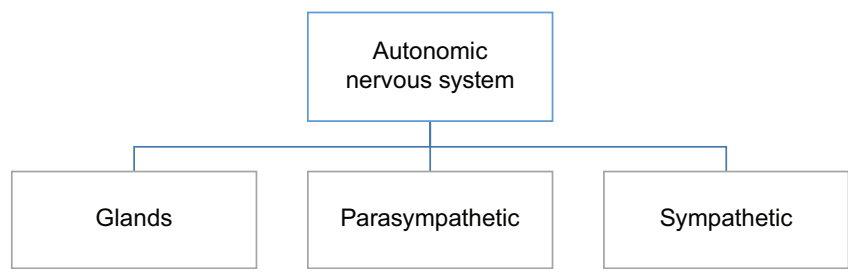

Figure 2: Control of smooth muscles, cardiac muscles, and glands

Mao et al. introduced that some research has examined the connection between sleep and hotel. In addition, they confirmed that there is a positive relationship between the traits of hotels and the quality of hotel guests' sleep. However, they did not gain greater vision into individual physical characteristics [4].

The study seeks to achieve a set of aims, the most important of which is to confirm the relationship between the activity of the parasympathetic system Biological Clock (CIRCADIAN RHYTHM) and healthy food metabolism. Second, to illustrate the diseases of the digestive system and their relationship to food metabolism and nutrition. And third, to highlight the changes that have occurred in the way of life and nutrition in society because of development, which led to the emergence of diseases. And finally, determine the appropriate time to eat breakfast, lunch, and dinner in line with the internal environment of the body and the external environment Biological Clock (CIRCADIAN RHYTHM) [5].

Plato linked satiety, lethargy, slackness, moderation in eating, and serenity of mind through a philosophical and spiritual view and emphasized that the treatment of disease should address the body as a whole and not the sick organ only. Aristotle said that the inhalation of air is not from the mouth and nose only but also the cells and the pores of the body breathe as well and that plants and production of oxygen in the early morning hours and the absorption of carbon dioxide and vice versa of the need for human oxygen and output of carbon dioxide in exhaled these operations whenever there is harmony between them led to the prevention [6].

Over the past centuries, diseases did not appear among humans in this widespread due to change many of the behaviors that people are accustomed to especially Egyptian old farmer which are in line with nature, including waking up early with the onset of light and eating breakfast foods that are produced from the environment, which may be characterized by a decline in the economic well value [7].

And then go out to work and when you return home at the end of the day at sunset time, one should have dinner between the time of Maghrib and Ishaa then go to bed early as a result of an early wake-up. Consequently, family members stop eating healthy food. The technological advances and modern developments behavior of individuals have changed and increased their aspiration for each new thing without paying attention to the form, composition, and timing of food in addition to changing the sleep timing for most individuals resulting in eating meals at different times. As a result, every member of the family eats at a different time that killed the minutes in which everyone meets on meals time and its positive impact on public health [8].

Wisdom manifested in his nature, which created people there are certain timings where the body is at full activity, vitality and can do all the natural processes that it needs to carry out all the functions of the representation of diet properly reaches healthy body that is free of disease and able to do the muscular and mental effort. The universe is based on that harmony, consistency, and coherence between the human (internally) and nature (external) which is considered the biological human time. When a change happens to these cosmic systems, the human's body begins to face stress, fatigue, and functional deficiencies of the body, and thus the emergence of diseases and illness in the body, and we start to search for the causes without referring to the nature creation. Therefore, the importance of the current study is in identifying the relationship between the Biological Clock (CIRCADIAN RHYTHM), the individual's food metabolism, the timing of eating meals, and the extent of its relationship to the body's illness [9].

\section{Parasympathetic system}

The parasympathetic system intervenes to regulate the body's function during rest, such as sleep and digestion - reduces the heart rate, increases 
Table 1: The study sample of Egyptians and foreigners according to the incidence of diseases

\begin{tabular}{|c|c|c|c|c|c|c|c|c|}
\hline \multirow[t]{2}{*}{ Parameter } & \multicolumn{8}{|c|}{ Diseases } \\
\hline & Sugar & Obesity & Liver & Diseases of the colon & Gallbladder disease & Other diseases & No diseases & Total \\
\hline \multicolumn{9}{|l|}{ Foreigners } \\
\hline Number & 1 & 8 & 0 & 0 & 0 & 6 & 125 & 140 \\
\hline Percentages & 1 & 6 & 0 & 0 & 0 & 4 & 89 & 100 \\
\hline \multicolumn{9}{|l|}{ Egyptians } \\
\hline Number & 10 & 13 & 3 & 8 & 4 & 8 & 114 & 160 \\
\hline Percentages & 6 & 8 & 2 & 5 & 3 & 5 & 71 & 100 \\
\hline \multicolumn{9}{|l|}{ Mean } \\
\hline Foreigners & 3 & & & & & & & \\
\hline Egyptians & 8 & & & & & & & \\
\hline \multicolumn{9}{|l|}{ SD } \\
\hline Foreigners & 4 & & & & & & & \\
\hline Egyptians & 2 & & & & & & & \\
\hline
\end{tabular}

stomach motility, increases secretions, and attacks. This system is also known as the basis for what is known as the phenomenon of dawn by converting the thyroid hormone into what is known as rest and digestion, and it is one of the three parts of the autonomic nervous system, as shown in Figure 2. The structured parasympathetic device work by issuing signals across light (with the beginning of the Biological Clock) through the eye when you realize the light of the morning, starting from 6 o'clock until seven in the morning and from 6 o'clock until seven in the evening to move through the spinal cord signals to issue the necessary hormones to stimulate the secretion of digestive enzymes during the enzymes salivary necessary metabolism in the digestive system glands in the abdominal area and then the parasympathetic system sends signals that stimulate the activity of the stomach and intestines (internally) and activates both the liver and pancreas and stimulates the gallbladder in addition to stimulating the genitals and becomes the digestive system fully prepared and completed activity (peak) by connecting internal elements by the external environment. Tracking phase of the summit excretion stage basal (basal status) less than the system activity and carrying the enzymes and the activity of glands turn the intestine to inactivity and less secretion of the pancreas and works sympathetic to increase breathing and pumping blood glucose, rapid heart rate [2].

Olshansky et al. 2008 and Omar et al. emphasized that at certain times, the sympathetic system begins to function at the need for speed (fight or flight), and the activity moves to the heart and increases in intensity with fever and digestion to the activity of other parts of the body. The brain begins to set a specific fixed program with the time, which signals the beginning of the activity time of the body and the digestive system [5], [10], [11].

\section{The role of the parasympathetic nervous} system in metabolic syndrome

The previous image refers to the incision Parasympathetic nervous system and its impact on the different organs of the human body which activate secretions of digestive enzymes and intestinal dramatically during periods of the day affected by the parasympathetic nervous system, which leads to the lack of any problems in digestion if linked to food systems [12].

Many researchers have shown that there is a change in the body mass of children in the last decades, and they attributed this to the interference of brain signals resulting from the disruption of those times to the occurrence of accidents. The secretion of insulin is linked to biological hourly closely and when a malfunction in the metabolism resulting in an imbalance in the secretion of insulin, which human affects diabetic and eating nightscape leads to a response to endocrine glands abnormally and increase the desire to eat food energy in the evening periods, giving thus vague references to the brain and the different rhythm of body temperature, sleep, and excessive insulin secretion and the accumulation of fat in the abdomen, heart disease, and blood vessels and irregular process of metabolism in line with the regularity of natural physiological (metabolic disorders') and thus obesity, were confirmed by Shakoor [13] and Schiller [14] that the value of the individual's basal metabolism during sleep (nighttime periods) decreases by $10 \%$ of the normal.

The fact that we all know that late night eating syndrome leads to that an individual does not have breakfast and even giving up on it at all (morning anorexia) [15], [16].

The main defect that causes the disease in the digestive system is due to the occurrence of a defect in the parasympathetic nervous system and its incompatibility with the external environment and the metabolism process [17].

Most of the articles focused on research dealing with food and nutrition value and the amount of the meal and focus on activities without paying attention to the importance of optimal timing for meals and even determine the times of food systems are incompatible with the autonomic nervous system and the external environment and the limited view of the environment and the surrounding medium of forbidding eating in front of the television, the internet, and other [6].

Some people believe that eating one meal a day like breakfast with fat content may be ideal for the application of diet systems and weight loss and that on the contrary, completely handled meals such as breakfast and dinner and content of the diet moderately better as proven by experience that the metabolism is 
in the one his meal a negative effect on the liver, insulin secretions, and glucose levels, which leads to obesity, as well as the energy to work is negatively affected [18].

Moreover, some studies have shown that children who sit the most in front of the TV are exposed to an increase in the rate of food consumption by $105 \%$ of the others who watch less [15], [19].

In addition, the participation of the family at least 3 times in the family meals per week leads to a healthy diet, and adherence to the set appointments leads to an appetite [20].

Despite the availability of diabetes medications, changes in lifestyle, behavioral, and cognitive patterns have an impact on the ineffectiveness of health outcomes [21].

Many have tried to strive by establishing regulated diets for obese patients through dieting regimens, including what is transmitted from the west and making a list of prohibited foods and foods. Similarly for diabetics - people with liver and gallbladder diseases - measuring secretions of the endocrine measuring the metabolism grassroots and others. Most researchers start to search about the quality of food, medicines, disincentives, and others trying to focus on the quality of inputs without standing even for a period to discover the fact that the body system is fixed and we must find out what has been disturbing the performance of that system and respect it [22].

\section{Study hypothesis}

There is a statistically significant relationship between eating the three meals at a specific time and hour (according to the Biological Clock) (CIRCADIAN RHYTHM) and between food metabolism and the prevention of disease and outbreaks.

\section{Research Methodology}

Questionnaire forms were distributed to a random sample of Egyptian and foreign guests at resorts and tourist hotels in Hurghada between March and September of the year 2021. The survey included a range of inquiries about nationality, age, weight, and height. And whether the individual suffers from obesity, in addition to recognizing the type of effort expended, the number of hours of sleep, the number and quality of meals eaten per day. Furthermore, whether there are hereditary diseases and the type of diseases in case of infection. The study needed to know the time of sleep and the time of awakening to determine whether there is a relationship between them and the three meals and their dates and the consumption of healthy food. It was important to make sure how keen individuals to eat meals on time or not, and the extent of their commitment to it. The main reason refers to finding communication points between what the hotels services offer and progress of clients including no desire contrary to the health and verification of the interest of individuals, level of awareness, and level of education aware educational and health they have.

\section{The study sample}

The study sample was 304 questionnaires (Table 1). Of which, 300 are valid and four are invalid. One hundred and forty of them are for foreigners and 160 are for Egyptians. After that, comparing the sample and extracting percentages and frequencies to discover the different relationships, which contributed to the development of the recommendations, concluded by the study.

\section{Statistical analysis}

In this study, descriptive analysis of the collected data - percentages-frequencies-Arithmetic mean 2 was used to determine the relationship between a set of variables and to clarify and clarify the explanation.

\section{Results and Discussion}

Through the theoretical and field study, several results were reached to study the relationship between the time of awakening and the time of eating meals and between the sympathetic system (the human's Biological Clock) (CIRCADIAN RHYTHM) and its role in harmonizing external influences and food metabolism.

It is clear from Figure 3 that the sample of foreigners is in the age group of 26-41 years, with a percentage of $37 \%$, and in the second rank, it was from 18 to 25 years, where the total percentage of foreigners is $31 \%$, then $42-60$ with a percentage of $15 \%$. While the Egyptians, the age group of 26-40 years was the largest of the samples with a percentage of $26.25 \%$ followed by the age group of $42-60$ years at a percentage of $22 \%$.

The results show more dominant in females by $62.2 \%$ for foreign guests and the mean is 1.62 and a standard deviation 0.487 and in case of Egyptians the men is more dominant with $52.6 \%$ and females $47.4 \%$ with a mean ratio of 1.4 and a standard deviation 0.50 .

The results showed that the vast majority of the foreigner's sample had an ideal weight at a rate of $67 \%$, then those who were underweight $10 \%$, and $12 \%$ of those who suffered from overweight, and their weight did not exceed an extreme. As for the Egyptians, the highest percentage of those suffering from excess 


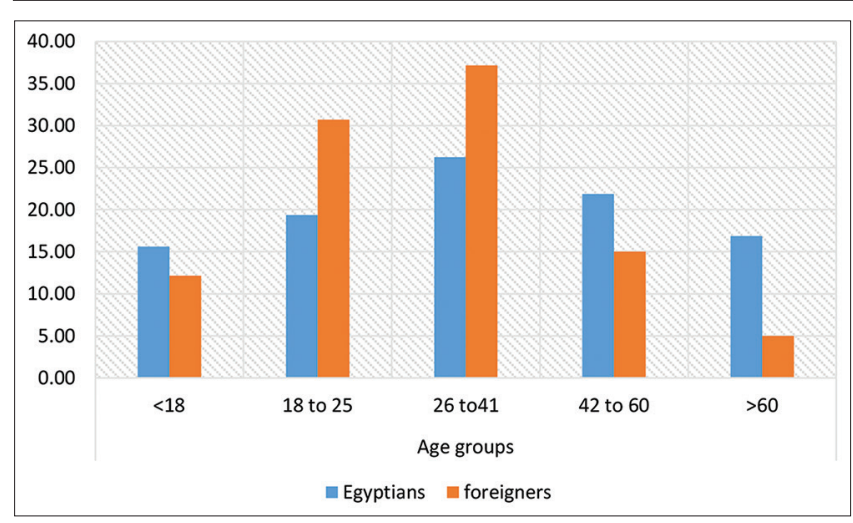

Figure 3: Age groups in the study sample

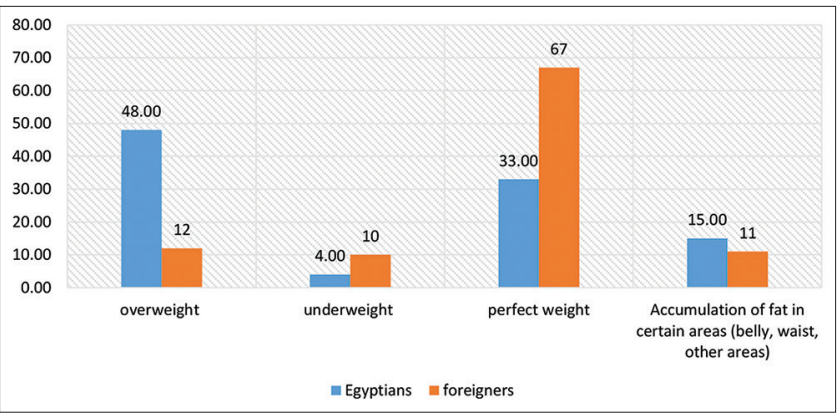

Figure 4: The study sample of Egyptians and foreigners, according to weight

weight and fat accumulation was in certain areas (abdomen-waist-other areas) at a rate of more than $48 \%$, or more than $15 \%$, as shown in Figure 4.

As for the nature of daily work between the Egyptians and foreigners, it became clear from the results that the very light work (read-watch TV-sitting) was accounted for $41 \%$ while light work (houseworkwalking slowly-shopping) was accounted for $33 \%$ and $15 \%$ work heavy (work in the fieldwork that requires movement with mental effort-power games), and finally, an average work of $14 \%$ for foreigners. On the contrary, for the Egyptians, it is clear from the results of the study that $28.5 \%$ of the samples do light work (housework-walking slowly-shopping) and $24.1 \%$ of laborers work in the field strong), $19 \%$ medium work (deep cleaning-fast walking and playing tennis), and $17.5 \%$ work very heavy (lifting heavy materials-swimming-running-cycling).

Although the Egyptians are the top in hard work percentage, it was noted that they score the most diseases prevalent obesity which is due to the irregular dates of eating meals and stop having breakfast, as it turned out in Table 2, and late time sleep. This was confirmed by Zygmunt and Stanczyk [17] that the parasympathetic system has certain periods that are higher in the enzyme secretions and lower at the time of basal metabolism.

It is clear from the results of the study that the disease is not attributable to the genetic factor, as the results showed that $89 \%$ of the foreign samples do not suffer from any hereditary diseases, while $11 \%$ suffer from hereditary diseases. It was also clear from the results that $71 \%$ of the Egyptian samples do not suffer from any hereditary diseases, and $29 \%$ suffer from some hereditary diseases, which confirms that the hereditary factor is not hereditary.

The results showed that $82 \%$ of foreigners get enough sleep, which is $7-8 \mathrm{~h}$ of sleep per day. The results showed that $39.4 \%$ of Egyptians slept from 8 to $7 \mathrm{~h}$ a day, while $37.2 \%$ slept from 6 to $5 \mathrm{~h}$ a day.

The study showed that $57 \%$ of foreign guests get up early from 6 to 8 in the morning, while $34 \%$ get up very early before 6 in the morning. As for the time of awakening for the Egyptian sample, the study showed that $30.7 \%$ of the samples wake up from 6 to 8 in the morning, $26.3 \%$ wake up early before 6 , and $61 \%$ wake up at $8-10$ in the morning and $11.7 \%$ and get up late afternoon.

It was also clear from the results that $53 \%$ do not practice any physical activity after waking up, and $69.3 \%$ of Egyptians do not practice any physical activity after waking up. As for the time of sleep, 38\% of the Egyptian samples sleep at $2 \mathrm{am}$, and the same percentage (38\%) sleep from 1 to $11 \mathrm{am}$, and this result is clear. As for bedtime, the results showed that $50.5 \%$ of the foreigners slept starting at 1-11 in the morning, while 31.5 fell asleep very late starting at 2 in the morning. While $18 \%$ sleep early, starting from $8-10$ in the evening.

Figure 5 shows the great interest of foreigners who eat three meals a day, with a rate of $73 \%$ of the sample, while $13 \%$ eat breakfast and dinner, and $9 \%$ do not have breakfast. The results also showed that $65 \%$ of the Egyptian sample eat three meals a day, $12 \%$ eat only two meals (lunch and dinner), leaving breakfast, and $12 \%$ are having lunch and breakfast while leaving the dinner. Where there is a statistically significant close relationship between the percentage of late dinner starting from midnight to late hours and the reluctance to eat breakfast in the early hours of the day from loss of appetite in the morning, even if I wake up early and this was confirmed by both [23].

The study showed, as shown in Table 3, that the breakfast time for foreign guests starts at 8-10 am at a rate of $29 \%$, while $43 \%$ of foreign guests eat it at 10-12 a.m. The study also showed that the time for Egyptian guests to eat breakfast starts at 8 a.m. before 10 a.m., at a rate of $19 \%$, while $28 \%$ ate it from 10 a.m., while $19 \%$ eat breakfast from 6 to 8 in the morning.

Foreigners eat lunch from 2 to 4 in the evening, with a percentage of $40 \%$, and $24 \%$ of them eat lunch from 12 to 2 in the evening, and $31 \%$ of them eat it from 4 in the evening. As for the time of eating lunch for Egyptians, the results showed that 34\% take it from 
Table 2: Breakfast, lunch, and dinner times for Egyptians and foreigners

\begin{tabular}{|c|c|c|c|c|c|c|c|c|c|c|c|c|c|c|c|c|}
\hline \multirow[t]{2}{*}{ Parameter } & \multicolumn{5}{|c|}{ Breakfast time } & \multicolumn{5}{|c|}{ Lunch time } & \multicolumn{6}{|c|}{ Dinner time } \\
\hline & $\begin{array}{l}\text { Before } \\
6-8\end{array}$ & $\begin{array}{l}\text { From } 8 \\
\text { to } 10\end{array}$ & $\begin{array}{l}\text { From } 10 \\
\text { to } 12\end{array}$ & $\begin{array}{l}\text { Not eat } \\
\text { breakfast }\end{array}$ & Total & $\begin{array}{l}\text { From } 12 \\
\text { to } 2\end{array}$ & $\begin{array}{l}\text { From } 2 \\
\text { to } 4\end{array}$ & $\begin{array}{l}\text { From } \\
4 \text { to } 6\end{array}$ & $\begin{array}{l}\text { Not eat } \\
\text { lunch }\end{array}$ & Total & $\begin{array}{l}\text { From } 6 \\
\text { to } 8\end{array}$ & $\begin{array}{l}\text { From } 8 \\
\text { to } 10\end{array}$ & $\begin{array}{l}\text { From } 10 \\
\text { to } 12\end{array}$ & $>12$ & $\begin{array}{l}\text { Not eat } \\
\text { dinner }\end{array}$ & Total \\
\hline \multicolumn{17}{|l|}{ Foreigners } \\
\hline Number & 20 & 40 & 60 & 20 & 140 & 33 & 56 & 43 & 8 & 140 & 7 & 35 & 42 & 38 & 18 & 140 \\
\hline Percentages & 14 & 29 & 43 & 14 & 100 & 24 & 40 & 31 & 6 & 100 & 5 & 25 & 30 & 27 & 13 & 100 \\
\hline \multicolumn{17}{|l|}{ Egyptians } \\
\hline Number & 30 & 62 & 44 & 24 & 160 & 33 & 51 & 55 & 1 & 140 & 25 & 22 & 56 & 31 & 26 & 160 \\
\hline Percentages & 19 & 39 & 28 & 15 & 100 & 21 & 32 & 34 & 1 & 88 & 16 & 14 & 35 & 19 & 16 & 100 \\
\hline \multicolumn{17}{|l|}{ Mean } \\
\hline Foreigners & 35 & & & & & 35 & & & & & 31 & & & & & \\
\hline Egyptians & 40 & & & & & 35 & & & & & 34 & & & & & \\
\hline \multicolumn{17}{|l|}{ SD } \\
\hline Foreigners & 19 & & & & & 20 & & & & & 15 & & & & & \\
\hline Egyptians & 17 & & & & & 25 & & & & & 14 & & & & & \\
\hline
\end{tabular}

Table 3: Chi-square value for relation in the study sample

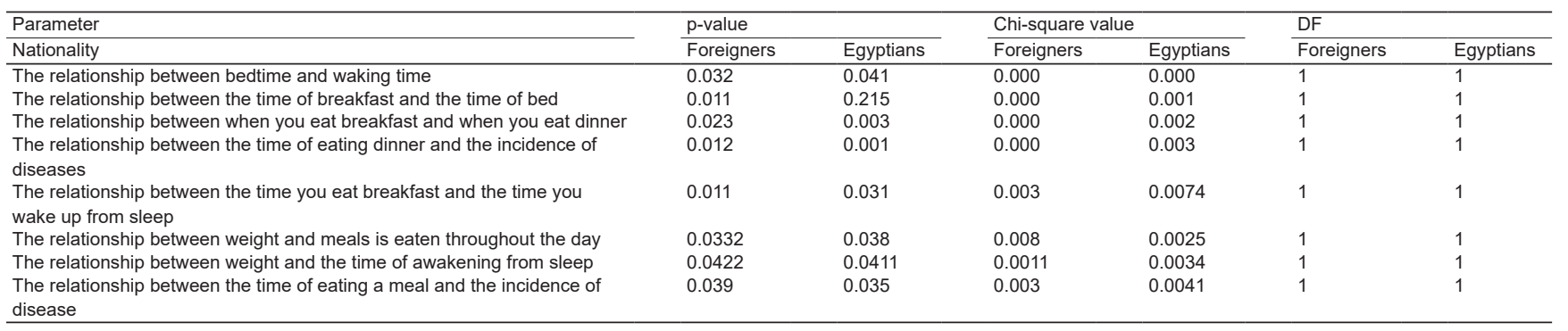

4 to $6 \mathrm{pm}$, while $32 \%$ eat lunch from 2 to 4 during the evening, $21 \%$ after $12-2 \mathrm{pm}$.

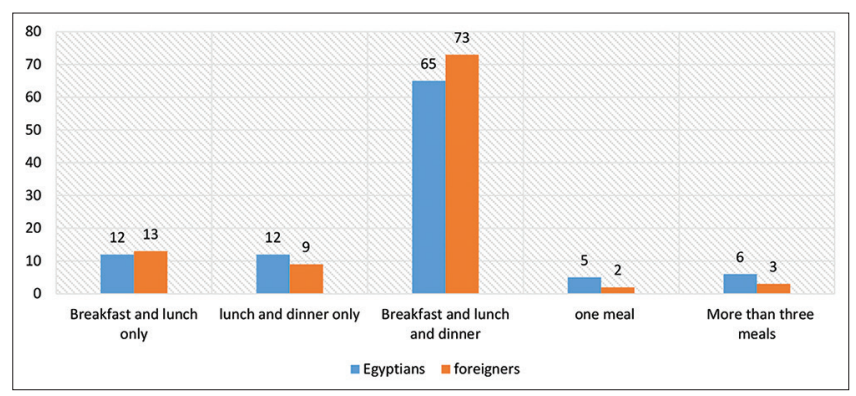

Figure 5: Meals are eaten throughout the day by Egyptians and foreigners

As for the timing of dinner for foreigners, it showed that $30 \%$ of the total sample ate dinner late from 10 -noon, while $27 \%$ had an afternoon, $25 \%$ in $8-10$, and $16 \%$ they do not eat dinner. As for the timing of Egyptians eating dinner, it was found that $35 \%$ of the total samples eat dinner late from 10 to noon, $19 \%$ of the Egyptian samples eat dinner $>12$, and $16 \%$ of the Egyptian samples eat dinner, while $16 \%$ do not eat dinner.

The results of the questionnaire showed that $52 \%$ of the foreigners' samples do not adhere to the fixed time for eating when eating outside the home, while $35 \%$ of the foreigners do not adhere to the fixed time for eating at home, and $13 \%$ of the time when they are at home. The results of the study also revealed that $51 \%$ of the Egyptian samples do not adhere to the fixed time for eating when eating outside the house. While $25 \%$ adhere to the appointment as much as possible, $24 \%$ adhere to the fixed time for eating outside the house.

The results of the research for foreigners showed that $73 \%$ do not follow a certain diet and $86.1 \%$ of Egyptians do not follow a specific diet.
It is clear from Figure 6 that a sample of foreigners is estimated at $45 \%$ who are interested in searching for information on food and nutrition regularly, while $22 \%$ are interested in searching for information about the disease. About 33\% of foreigners are not interested in searching for information on food and nutrition, whether with health or disease. The results also showed that $33 \%$ of the Egyptian samples are not interested in looking for information on food and nutrition except in the event of an illness, while $33 \%$ are not interested in looking for nutrition information, and $33 \%$ are not interested in education or information and $35 \%$ are searching for information on food and nutrition regularly.

\section{Chi-square test}

The Chi-square distribution is one of the commonly used probability distributions, as it has many applications to the degree that it can be said that it ranks second in the normal distribution. The Chi-square distribution, like the $t$ distribution, depends entirely on the degrees of freedom. Confidence was $<0.05$.

From the table above, there is a statistically significant relationship between sleep and wake-up time for confidence degree $<0.05$, whether for Egyptians or foreigners, and freedom 1, which is not high. It means that the fewer degrees of freedom, the greater the distortion of distribution and getting away from symmetry. The results also show that there is a statistically significant relationship between the time of breakfast and the time of bed for Egyptian and foreign guests, with a confidence degree of $<0.05$ with 1 freedom. As seen from the above data, there is a statistically significant relationship between breakfast 


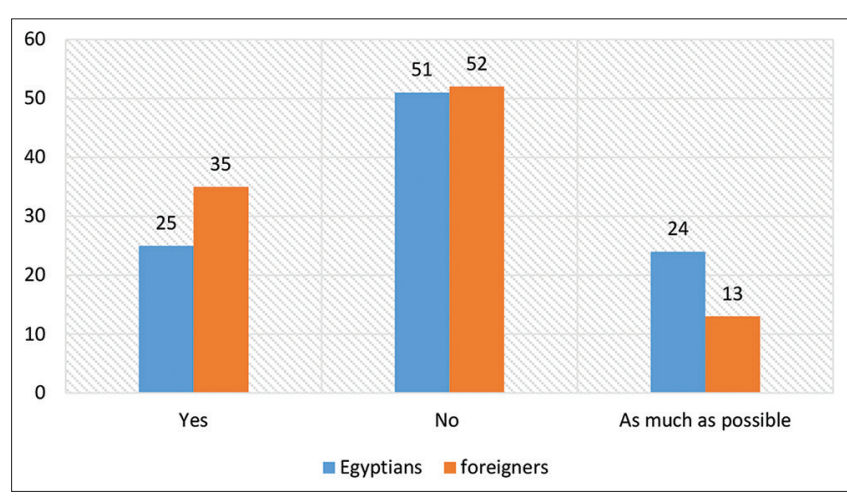

Figure 6: Adhering to the timings of eating outside the home

and the date of dinner with a confidence degree $<0.05$, whether for Egyptians or foreigners, and freedom is 1 , which is not high, and it means that the fewer degrees of freedom, the greater the distortion of distribution and getting away from similarity.

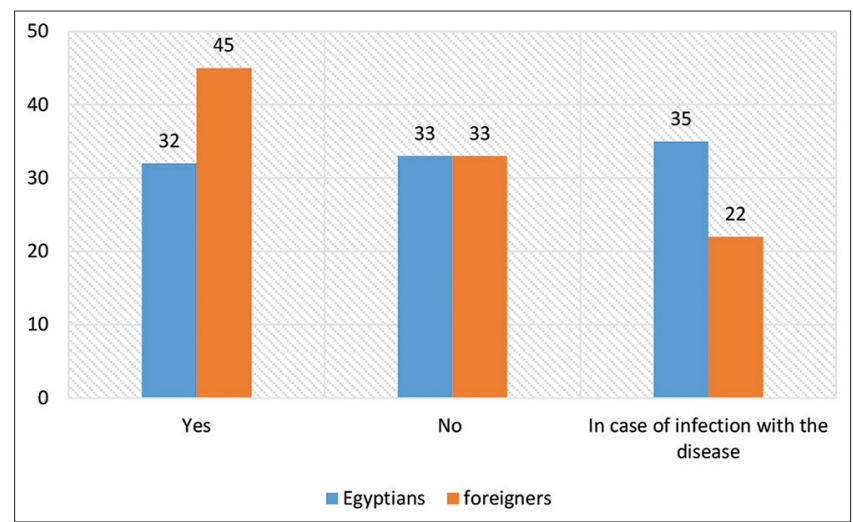

Figure 7: Finding information about the food, nutrition, and digestive system of foreigners and Egyptians

As it is shown in Table 3, there is a statistically significant relationship between dinner and the infection with diseases for confidence degree $<0.05$ for the Egyptians guests and freedom of 1 which is not high. It means that the fewer degrees of freedom, the greater the distribution of distortion and getting away from symmetry.

It is clear from the previous table that there is a statistically significant relationship between the time of having breakfast and the time of awakening for the Egyptian guests, with confidence $<0.05$.

From the previous data, there is a statistically significant relationship between the body weight and the meals eaten throughout the day, with a confidence degree of $<0.05$ for foreign guests.

It is clear from Table 3 that there is a statistically significant relationship between the body weight and the time of awakening from sleep, with a confidence degree $<0.05$ for foreign guests.

The previous table shows that there is a statistically significant relationship between the time of a meal and the infection with diseases for confidence degree $<0.05$ for foreigners and freedom of 1 , which is not high. It means that the fewer degrees of freedom, the greater the distortion of distribution getting away from symmetry as shown in Figure 7.

From the foregoing results, we realize the expansion of interest in nutrition in all countries of the world and the interest of specialists in what people have of information about food and nutrition and its role in treating or avoiding some diseases. Therefore, we must correct the concepts, identify the needs, and increase nutritional education, with attention to behavioral changes among people that result in an improvement in their health, nutrition, and nutritional status.

The timing of meals eaten outside the home contrasts with the nature of some individuals in the Egyptian sample. About $25 \%$ of them try to comply as much as possible and the majority cannot by $55 \%$. As for foreigners, the largest percentage was $37 \%$ who could not eat the meal on time and between $25 \%$ and $33 \%$ are eating and trying to comply which requires modifying the timing of serving food by the hotels depending on the nature of the body and the biological system of nature. This is in addition to the irregular sleeping hours among the Egyptians and the delay in bedtime. Consequently, the late eating of dinner and as a result the failure to have breakfast even in the case of waking up early. Ends up simply by having only two meals lunch and dinner. Or by the lack of regularity in the times of eating meals where there is a statistically significant close relationship between having dinner late and the reluctance to eat breakfast in the early hours of the day even in the case of waking up early. This loss of appetite is called morning anorexia, and this was confirmed by Wilson (2011) [24].

Obesity and susceptibility to diseases are on the rise among Egyptians, even though the research sample is from young people up to the age of 40 , and therefore, it is expected that these rates will rise with age. On the contrary, we find that foreigners are committed to eating the three meals on time as much as possible and adhere to sleep early and wake up early. As a result, they enjoy the ideal weight and does not subject to digestive system diseases due to the high rate of food culture they have [25].

\section{Recommendations}

1. Linking the close relationship of the parasympathetic system Biological Clock (CIRCADIAN RHYTHM) to a healthy metabolism of the body through the parasympathetic nervous system, the external times of sleep, and wakeup, and having meals at the correct time

2. Getting up early, eating breakfast, and then applying early exercise play a major role in extending human life and living as long as 
possible in good health, and enjoying an ideal body

3. Paying attention to having the three meals on time, as indicated by the study, without canceling any of them

4. Changing the recently acquired habits of sleeping and having meals at late times so as not to affect the physical health, performance, and mood of individuals

5. Adjusting the timing of serving meals in hospitality establishments to match the body's systems, starting from breakfast at six in the morning and up to a maximum of nine. Lunch is served from 12 noon until 3 o'clock, and dinner is from 5 until 8 at the most

6. Hospitality establishments should link between the guests' loyalty and the improving guests' experience and satisfaction of adjusting meals timing that respects the body's systems

7. Raising the food culture among the Egyptians.

\section{Conclusion}

The brain needs constant signs (morning and evening) from the inside and the outside for constant food metabolism to maintain the rhythm of the physiological self in harmony with the production and function of the parasympathetic system, which emphasizes the importance of controlling the timing of having breakfast, lunch, and dinner to accommodate internally with the activity of the body and to working internally and externally in harmony to maintain a healthy body without any diseases and to enjoy the ideal body weight.

\section{References}

1. Shalaby MN, Liu JY, Kassem MM, Saad M. Circulating hematopoietic stem cell and some physiological parameters in different training programs. Life Sci J. 2012;9(1):965-71.

2. Ortega RM, Redondo MR, Zamora MJ, López-Sobaler AM, Quintas ME, Andrés P, et al. Relationship between the number of daily meals and the energy and nutrient intake in the elderly. Effect on various cardiovascular risk factors. Nutr Hosp. 1998;13(4):186-92.

PMid:9780751

3. Buysse DJ, Reynolds CF, Monk TH, Berman SR, Kupfer DJ. The Pittsburgh sleep quality index: A new instrument for psychiatric practice and research. Psychiatry Res. 1989;28(2):193-213. https://doi.org/10.1016/0165-1781(89)90047-4

4. Mao Z, Yang Y, Wang M. Sleepless nights in hotels? Understanding factors that influence hotel sleep quality. Int $\mathrm{J}$ Hosp Manag. 2018;74:189-201.

5. Kreier F, Yilmaz A, Kalsbeek A, Romijn JA, Sauerwein HP, Fliers $\mathrm{E}$, et al. Hypothesis: Shifting the equilibrium from activity to food leads to autonomic unbalance and the metabolic syndrome. Diabetes. 2003;52(11):2652-6. https://doi. org/10.2337/diabetes.52.11.2652

\section{PMid:14578282}

6. Rolfes SR, Pinna K, Whitney E. Understanding Normal and Clinical Nutrition. Cengage Learning; 2014.

7. Shalaby MN, Sakoury MM. The role of physical activity on the support and enhance the natural behavior of stem cells and chosen physiological variables for players athletics. DRASSA J Dev Res Sport Sci Act. 2018;4(1):74-92.

8. Dudeja P, Singh A, Kaur S. Food Safety Implementation: From Farm to Fork. India: CBS Publishers and Distributors Pvt. Limited; 2016.

9. Shalaby MN, Sakoury MM, Kholif MA, Alsayed NI. The role of amino acids in improving immunity and growth factors of volleyball players. J Adv Pharm Educ Res. 2020;10(4):141.

10. Olshansky B, Sabbah HN, Hauptman PJ, Colucci WS Parasympathetic nervous system and heart failure: Pathophysiology and potential implications for therapy. Circulation. 2008;118(8):863-71. https://doi.org/10.1161/ circulationaha.107.760405

PMid:18711023

11. Jain S, Namboodri KK, Kumari S, Prabhakar S. Loss of circadian rhythm of blood pressure following acute stroke. BMC Neurol. 2004;4(1):1-6.

12. Hussien S, Morad DF, Ibrahim NM, Shalaby MN. The effect of using an exercise-nutrition program on some physiological variables on diabetes patients. Indian J Forensic Med Toxicol. 2021;15(2):4030-9. https://doi.org/10.37506/ijfmt.v15i2.15005

13. Shakoor $S$, Rao $A Q$, Shahid $N$, Yaqoob A, Samiullah TR, Shakoor S, et al. Role of oral vaccines as an edible tool to prevent infectious diseases. Acta Virol. 2019;63(3):245-52. https://doi.org/10.4149/av_2019_301

PMid:31507189

14. Schiller $Y$. The anatomy and physiology of the sympathetic innervation to the upper limbs. Clin Auton Res. 2003;13(1):i2-5. https://doi.org/10.1007/s10286-003-1102-6

PMid:14673663

15. Coon KA, Goldberg J, Rogers BL, Tucker KL. Relationships between use of television during meals and children's food consumption patterns. Pediatrics. 2001;107(1):E7. https://doi. org/10.1542/peds.107.1.e7 PMid:11134471

16. Shalaby MN, Kholif MA, El Sayed KA. Effect of using some methods of hospitalization on the speed of return to normal and some physiological variables for volleyball players. Syst Rev Pharm. 2021;12(3):448-55.

17. Zygmunt A, Stanczyk J. Methods of evaluation of autonomic nervous system function. Arch Med Sci. 2010;6(1):11-8. https:// doi.org/10.5114/aoms.2010.13500

PMid:22371714

18. Fuse $Y$, Hirao A, Kuroda H, Otsuka M, Tahara $Y$, Shibata S. Differential roles of breakfast only (one meal per day) and a bigger breakfast with a small dinner (two meals per day) in mice fed a high-fat diet with regard to induced obesity and lipid metabolism. J Circadian Rhythms. 2012;10(1):1-12.

19. Jeffery RW, French SA. Epidemic obesity in the United States: Are fast foods and television viewing contributing? Am J Public Health. 1998;88(2):277-80. https://doi.org/10.2105/ ajph.88.2.277

\section{PMid:9491022}

20. Hammons AJ, Fiese BH. Is frequency of shared family meals related to the nutritional health of children and adolescents? Pediatrics. 2011;127(6):e1565-74. https://doi.org/10.1542/ peds. $2010-1440$ 


\section{PMid:21536618}

21. Shalaby MN, Sakoury MM, Hussien SS, Mohamed WG Heikalc HF, Rabeid MA, et al. The effect of using a suggested sport's diet on increased thyroid secretion and its effect on obesity. Syst Rev Pharm. 2021;12(1):805-17.

22. Shalaby MN, Fadl MA. Relative indicators and predicative ability of some biological variables on cardiac neural activity for volleyball players. Syst Rev Pharm. 2020;11(9):834-40.

23. Rosenberg ES, Dufort EM, Udo T, Wilberschied LA, Kumar J, TesorieroJ, etal.Association of treatmentwith hydroxychloroquine or azithromycin with in-hospital mortality in patients with
COVID-19 in New York State. JAMA. 2020;323(24):2493-502. https://doi.org/10.1001/jama.2020.8630

24. Lee YA, Hyun KJ, Sone $\mathrm{Y}$, Tokura H. Effects of bright or dim light during the daytime on digestive activity in humans. Naturwissenschaften. 2001;88(3):126-8. https://doi. org/10.1007/s001140100208

PMid:11402842

25. Allison KC, Hopkins CM. Eating disorders: Disorders of Underand overnutrition. In: Nutrition Guide for Physicians and Related Healthcare Professionals. Berlin: Springer; 2017. p. 63-72. 